\title{
Artesunate altered cellular mechanical properties leading to deregulation of cell proliferation and migration in esophageal squamous cell carcinoma
}

\author{
RUYI SHI ${ }^{1,2^{*}}$, HEYANG CUI $^{1,2^{*}}$, YANGHUI BI $^{1,2^{*}}, \mathrm{XUN} \mathrm{HUANG}^{3 *}$, BIN SONG $^{1,4}$, CAIXIA CHENG $^{1,2,5}$, \\ LING ZHANG $^{1,2,6}$, JING LIU ${ }^{1,7}$, CHANTING HE ${ }^{1,2}$, FANG WANG ${ }^{1}$, ZHIWU JIA ${ }^{1}$, BIN YANG ${ }^{1}$, JUAN WANG ${ }^{1,2}$, \\ JINYAO DONG $^{7}$, ZHIJIE DU $^{7}$, SHUAISHUAI XIAO ${ }^{7}$, YONGPING CUI ${ }^{1,2}$ and XIAOLONG CHENG ${ }^{1,8}$ \\ ${ }^{1}$ Key Laboratory of Cellular Physiology, Ministry of Education; ${ }^{2}$ Department of Cell Biology and Genetics, \\ Shanxi Medical University, Taiyuan, Shanxi 030001; ${ }^{3}$ Department of Materials Science and Engineering, Jinan University, \\ Guangzhou, Guangdong 510630; Departments of ${ }^{4}$ Oncology and ${ }^{5}$ Pathology, The First Hospital, Shanxi Medical University; \\ ${ }^{6}$ Department of Pathology, Shanxi Medical University; ${ }^{7}$ Department of General Surgery, The First Hospital; \\ ${ }^{8}$ Institute of Dissection, Shanxi Medical University, Taiyuan, Shanxi 030001, P.R. China
}

Received July 11, 2014; Accepted February 10, 2015

DOI: $10.3892 / \mathrm{ol} .2015 .2982$

\begin{abstract}
Esophageal squamous cell carcinoma (ESCC) is one of the most common types of cancer in China. Artesunate (ART) is used clinically as an anti-malarial agent and exhibits potent antiproliferative activity. In addition, ART has demonstrated remarkable antitumor activity, presenting a novel candidate for cancer chemotherapy. However, its effect on ESCC remains unknown. The present study analyzed the antitumor effects of ART in the KYSE-150 ESCC line by assessing cell proliferation, cell death, cell migration/invasion and the biomechanical properties of ART-treated KYSE-150 cells. ART treatment significantly suppressed the proliferation of KYSE-150 cells in a dose- and time-dependent manner, as assessed by MTT assay. Following treatment with $30 \mathrm{mg} / \mathrm{l} \mathrm{ART}$, the cell population in the $\mathrm{G}_{0} / \mathrm{G}_{1}$ phase and the level of cell apoptosis significantly increased from $54 \pm 1.5$ to $68.1 \pm 0.3 \%$, and from $4.53 \pm 0.58$ to $12.45 \pm 0.62 \%$, respectively. Furthermore, the cell migration and invasion of KYSE-150 cells treated with $30 \mathrm{mg} / \mathrm{l}$ ART was markedly inhibited. The cell membrane and biomechanical properties were investigated using atomic force microscopy, as targets of ART action. ESCC cells treated with $30 \mathrm{mg} / \mathrm{l}$ ART exhibited increased adhesive force, increased cytomembrane roughness and reduced elasticity compared with the control group (KYSE-150 cells without ART
\end{abstract}

Correspondence to: Professor Xiaolong Cheng, Institute of Dissection, Shanxi Medical University, 56 Xin Jian Nan Road, Taiyuan, Shanxi 030001, P.R. China

E-mail:sxcxl@sina.com

*Contributed equally

Key words: artesunate, esophageal squamous cell carcinoma, antitumor activity, biomechanical properties treatment). The biomechanical properties of KYSE-150 cells treated with $30 \mathrm{mg} / \mathrm{l} \mathrm{ART}$ were similar to those of the SHEE normal human esophageal epithelial cell line. In conclusion, the present study demonstrated that ART may inhibit cell proliferation and migration in ESCC through changes in the biomechanical properties of the ESCC cells.

\section{Introduction}

Esophageal cancer (EC) is the sixth leading cause of cancer-associated death worldwide, and the incidence and mortality associated with esophageal squamous cell carcinoma (ESCC) is highest in China in comparison with other countries (1). Current treatment options for cancer are based on surgery, chemotherapy and radiation therapy. However, the development of drug resistance and the severe side effects of chemotherapy remain unresolved problems in clinical oncology and reduce successful therapeutic outcomes of chemotherapy (2). Therefore, the identification of improved novel anticancer compounds is required. Artesunate (ART) is a semi-synthetic derivative of artemisinin extracted from the Chinese herb Artemisia annua and is a safe and effective anti-malarial drug (2). In addition to anti-malarial activity, previously published studies indicate that artemisinin and its derivatives are active against cells from a broad spectrum of types of cancer (3-8). Cell proliferation of $>70$ cell lines from different tumor types are inhibited by ART and its associated compound artemisinin $(9,10)$. However, the effects of ART on the growth, cell cycle, apoptosis, migration and invasion in ESCC have not yet been reported.

The structural information and biomechanical properties of cell surface membranes are important indicators for determining structural changes (11). The cell membrane acts as the exchange interface between the inside and outside of the cell (12). Changes in cell membrane structure can therefore directly influence the behaviors of cells, in addition to elucidating disease or differentiation processes $(13,14)$. However, the 
effects of ART on the biomechanical properties of cell surface membranes in ESCC remains unclear. Atomic force microscopy (AFM) is a powerful tool for obtaining high-resolution ultrastructural data from biological samples (15), exploring the shape of a single cell and the properties of the cellular membrane $(16,17)$. In particular, chemical functionalization of the AFM tip with various ligands has enabled the mapping of complementary receptors on model or cellular surfaces (18). AFM is now frequently used to detect cancer cell membranes in the context of anticancer drugs (19-21).

In the present study, the effects of ART on cell proliferation, cell cycle, apoptosis, cell migration, invasion and cell structure were evaluated. In addition, the cell surface membranes and biomechanical properties of the KYSE-150 ESCC cell line were detected using AFM-based single-molecule force spectroscopy in vitro.

\section{Materials and methods}

Cell culture conditions. The SHEE (human esophageal epithelial cell line) and KYSE-150 (ESCC) cell lines were obtained from the Key Laboratory of Cellular Physiology, Ministry of Education, Shanxi Medical University (Taiyuan, China). They were cultured in Dulbecco's modified Eagle's medium (DMEM)/F12 (GE Healthcare Life Sciences, Logan, UT, USA) with $10 \%$ fetal bovine serum (FBS; GE Healthcare Life Sciences) and incubated in a humidified atmosphere at $37^{\circ} \mathrm{C}$ with $5 \% \mathrm{CO}_{2}$. The cells were subcultured every 2-3 days. Exponentially growing cells were used throughout the study.

Drugs and reagents. ART was purchased from Guilin Pharmaceutical (Shanghai) Co., Ltd. (Guilin, China). MTT [3-(4,5-dimethyl-2-thiazolyl)-2,5-diphenyl-2-H-tetrazolium bromide] and dimethyl sulfoxide (DMSO) were purchased from Sigma-Aldrich (St. Louis, MO, USA). Matrigel Basement Membrane Matrix was purchased from BD Biosciences (Franklin Lakes,NJ,USA). An annexin V/propidium iodide (PI) double-staining kit was purchased from Nanjing KeyGen Biotech Co., Ltd. (Nanjing, China). Cell culture flasks, plates, centrifuge tubes and Transwell plates were purchased from Corning, Inc. (New York, NY, USA).

MTT assay. The MTT assay was used to assess KYSE-150 cell proliferation following treatment with various concentrations of ART. Briefly, KYSE-150 cells were seeded into a 96-well plate at a density of $5 \times 10^{3}$ cells/well with culture medium, as described above. Different concentrations of ART $(0,10,30$ or $50 \mathrm{mg} / \mathrm{l})$ were then added to the KYSE-150 cells to yield a final volume of $200 \mu 1 /$ well. KYSE-150 cell proliferation was measured at 24, 36 and $48 \mathrm{~h}$. Following incubation, $20 \mu \mathrm{l}$ MTT $(5 \mathrm{mg} / \mathrm{ml})$ was added to each well and the cells were incubated at $37^{\circ} \mathrm{C}$ for $4 \mathrm{~h}$. The medium was then removed from each well and replaced with $200 \mu \mathrm{l}$ DMSO. The optical density was determined at $490 \mathrm{~nm}$ with a microplate reader (M491 EON1/S-130306F; BioTek Instruments, Inc., Winooski, VT, USA). Each assay was repeated at least three times.

Cell cycle and apoptosis assay by flow cytometry. Based on the results of the MTT assay, the most effective concentration of ART $(30 \mathrm{mg} / \mathrm{l})$ was used to assess the cell cycle distributions and apoptosis rates of KYSE-150 cells treated with ART, compared with the control group (0 mg/l). Briefly, following treatment with ART for $48 \mathrm{~h}$, KYSE-150 cells were collected at a density of $1 \times 10^{6}$ cells $/ \mathrm{ml}$ and washed twice with phosphate-buffered saline (PBS). For the cell cycle assay, the cells were washed twice with $500 \mu 1 \mathrm{PBS}$ and then fixed in ice-cold $70 \%$ ethanol overnight at $4{ }^{\circ} \mathrm{C}$. The cells were concentrated by removing the ethanol and treated with $0.01 \%$ DNase-free RNase A (Nanjing KeyGen Biotech Co., Ltd.) for $10 \mathrm{~min}$ at $37^{\circ} \mathrm{C}$. Cellular DNA was stained with 0.05\% propidium iodide (PI; Nanjing KeyGen Biotech Co., Ltd.) for $20 \mathrm{~min}$ at $4^{\circ} \mathrm{C}$ in the dark. For the apoptosis assay, the cells were suspended in $500 \mu 1$ binding buffer (Nanjing KeyGen Biotech Co., Ltd.). Subsequently, $5 \mu 1$ annexin V and $5 \mu 1$ PI was added to each sample for $15 \mathrm{~min}$ in the dark. The cells were analyzed using a FACSCalibur flow cytometer (BD Biosciences) with CellQuest software (version 5.1; BD Biosciences). Each sample was run in triplicate.

Cell migration and invasion assays. KYSE-150 cells were cultured to $85 \%$ confluence in $25-\mathrm{cm}^{2}$ culture flasks and treated with or without $30 \mathrm{mg} / \mathrm{l}$ ART for $48 \mathrm{~h}$. For the migration assays, $1 \times 10^{5}$ cells in DMEM/F12 were seeded onto an uncoated insert chamber ( $8 \mu \mathrm{m}$; Corning, Inc.)w. The lower chamber contained culture media with $10 \%$ FBS. Following 24-h culture, invasive cells were stained using $0.1 \%$ crystal violet (Beyotime Institute of Biotechnology, Shanghai, China) and counted under a microscope (IX71-A12FL/PH; Olympus Corporation, Tokyo, Japan). Experiments were repeated three times. For the invasion assays, experiments were performed with the Matrigel-coated Transwell migration chambers; the remainder of the procedure was performed using the same methods as the migration assays.

Atomic force microscopy (AFM) analysis. The 3D morphology and biomechanical properties of KYSE-150 cells treated with ART $(0$ or $30 \mathrm{mg} / \mathrm{l})$ and SHEE cells were detected by AFM. AFM measurements were performed in aqueous solution at room temperature, using a 5500 atomic force microscope (Agilent Technologies, Inc., Santa Clara, CA, USA). AFM images were acquired in tapping mode and in contact mode using Si3N4 tips (NSC19, 0.68 N/m normal spring constant; Schaefer Technologie GmbH, Langen, Germany) and gold-coated tips (CSC 38; Schaefer Technologie GmbH), respectively. The spring constants of the cantilevers used for AFM force spectroscopy were $\sim 0.1 \mathrm{~N} / \mathrm{m}$. Adhesion and elasticity maps were obtained by recording $16 \times 16$ force-distance curves on areas of a given size $(2 \times 2 \mu \mathrm{m})$, calculating the adhesion force and elasticity modulus for each force curve and displaying these values as gray and colorized scale pixels, respectively. These maps qualitatively and quantitatively demonstrated the viscoelasticity of individual cells at the nanoscale level.

Statistical analysis. For statistical analysis, the data were subjected to an arcsine transformation. The transformed data were then analyzed by one way analysis of variance, General Linear Model, or Student's test using SPSS software, version 11.0 (SPSS, Inc., Chicago, IL, USA ) (22). P $<0.05$ was considered to indicate a statistically significant difference. 
A

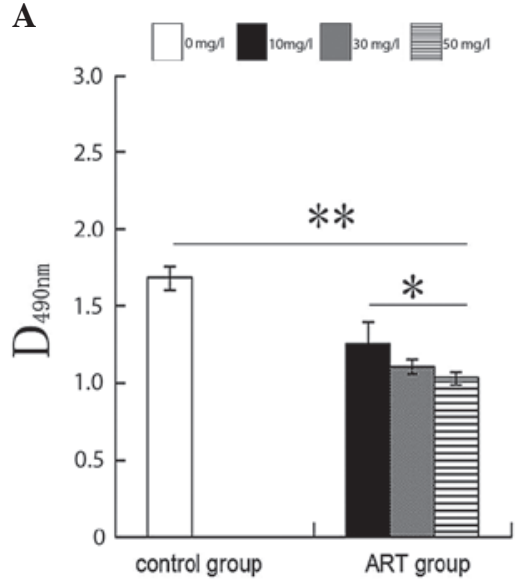

B

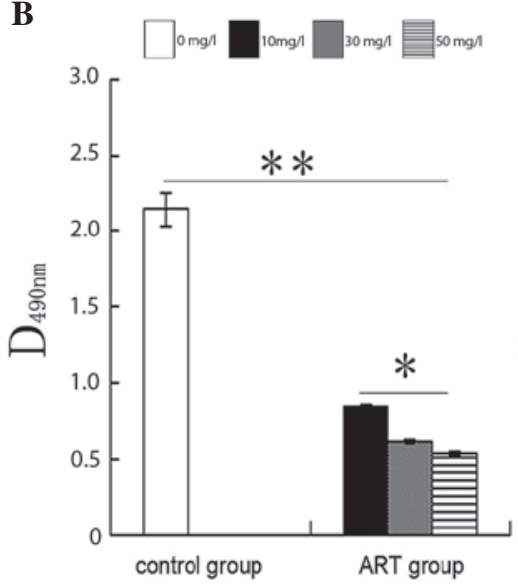

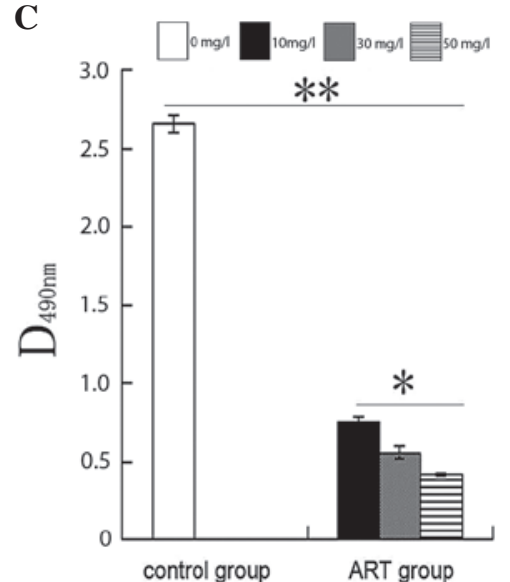

Figure 1. Proliferation of KYSE-150 cells treated with different concentrations of ART. Incubation of KYSE-150 cells with ART for (A) $24 \mathrm{~h}$, (B) $36 \mathrm{~h}$ and (C) $48 \mathrm{~h}$. The proliferation level of the control group was significantly higher than that of the ART groups; and that of the $10 \mathrm{mg} / \mathrm{l}$ ART group was significantly higher than that of the 30 and $50 \mathrm{mg} / 1$ ART groups. All data are presented as the mean \pm standard deviation. ${ }^{*} \mathrm{P}<0.05,{ }^{* *} \mathrm{P}<0.01$. ART, artesunate.

A

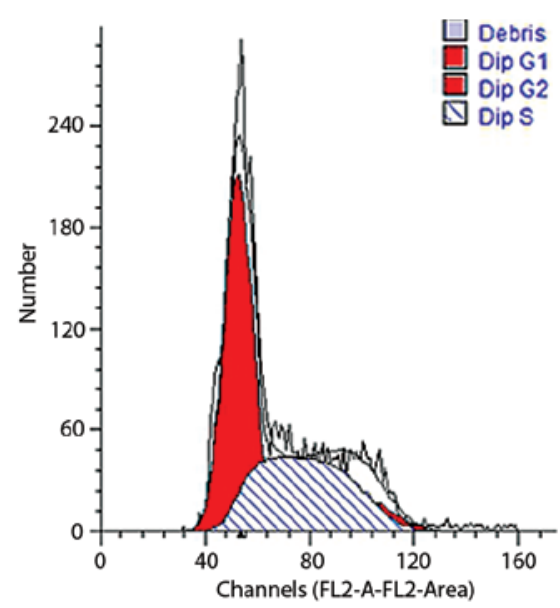

C

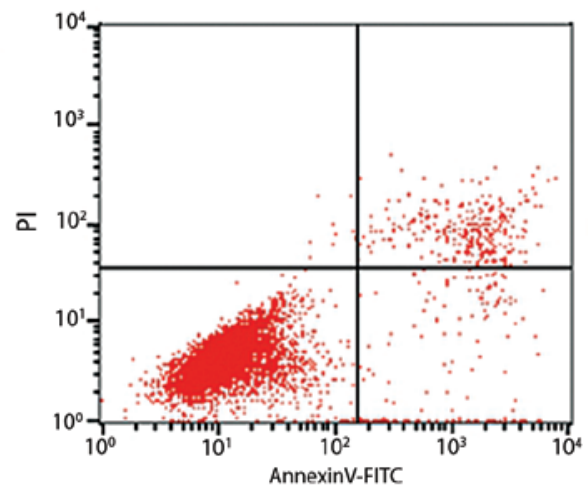

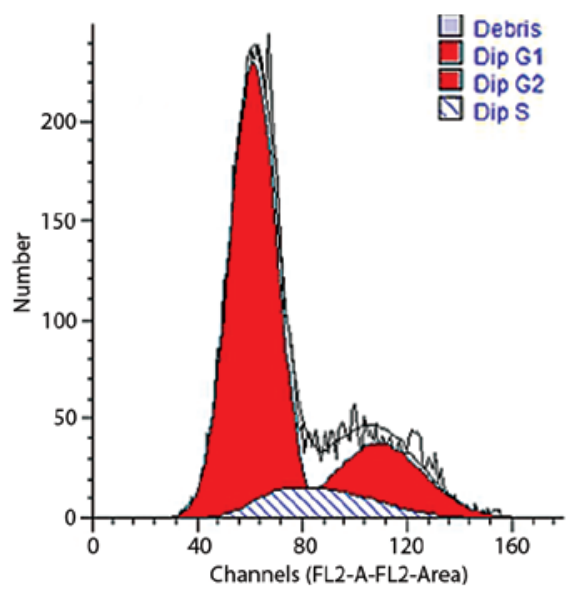

D

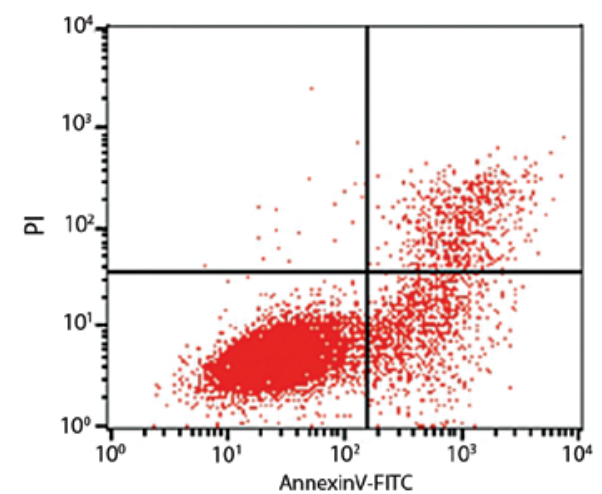

Figure 2. Cell cycle distribution and apoptosis analysis. Cell cycle distribution of the (A) control and (B) $30 \mathrm{mg} / 1$ ART-treated KYSE-150 cell groups. Apoptosis analysis of the (C) control and (D) $30 \mathrm{mg} / \mathrm{l}$ ART-treated KYSE-150 cell groups. ART, artesunate.

\section{Results}

Effects of ART on growth, cell cycle distribution and levels of apoptosis in ESCC cells. MTT assay and flow cytometry were used to assess KYSE-150 cell proliferation, cell cycle and apoptosis following treatment with different concentrations of ART. The proliferation of the control KYSE-150 cells not treated with ART (0 mg/l ART) was significantly higher than that of KYSE-150 cells incubated with other concentrations of ART (10, 30 and $50 \mathrm{mg} / \mathrm{l})$ at all time points (Fig. 1). Specifically, the proliferation levels of the $10 \mathrm{mg} / \mathrm{l}$ ART-treated group were significantly higher than those of the 30 and $50 \mathrm{mg} / \mathrm{l}$ ART groups at all time points. There was no significant difference in cell proliferation between the 30 and $50 \mathrm{mg} / \mathrm{l}$ ART groups at all time points (Fig. 1). ART markedly inhibited the growth of KYSE-150 cells in a dose- and time-dependent manner. 

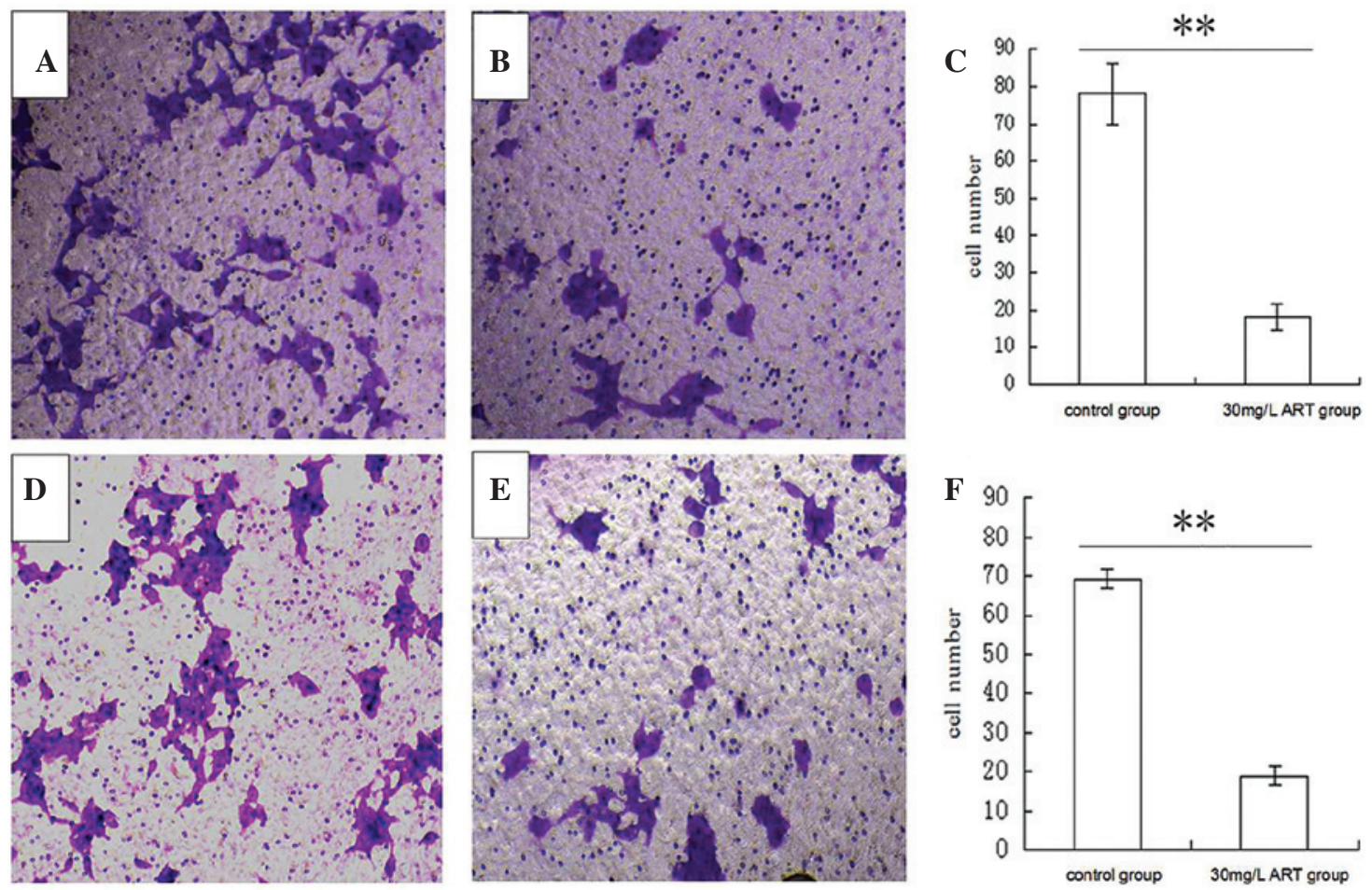

Figure 3. Transwell migration and invasion assay on KYSE-150 cells treated with ART for $24 \mathrm{~h}$. Migration of the (A) control group and (B) $30 \mathrm{mg} / \mathrm{l}$ ART groups. (C) Statistical analysis of migration. Invasion of the (D) control and (E) $30 \mathrm{mg} / \mathrm{l}$ ART groups. (F) Statistical analysis of invasion. The relative ratio of invasive cells per field is presented. All data are presented as the mean \pm standard deviation." $\mathrm{P}<0.01$. ART, artesunate.
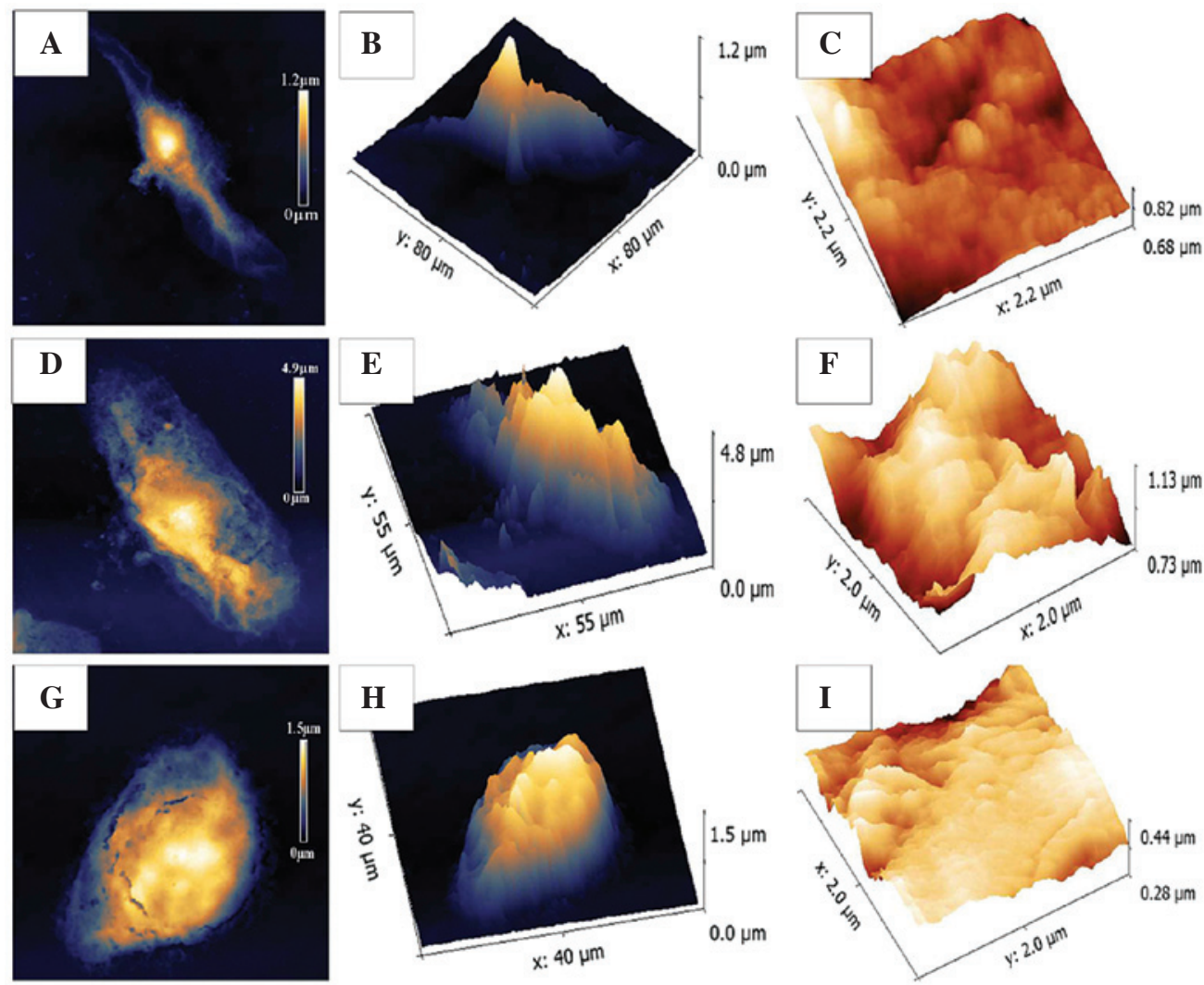

Figure 4. AFM images of KYSE-150 and SHEE cells. (A) 2D and (B) 3D AFM images of KYSE-150 cells cultured in vitro for $48 \mathrm{~h}$ without ART. The morphology of these cells indicated they were spindle in nature (size: 80x80 $\mu \mathrm{m}$ ). (C) The ultrastructure of an untreated KYSE-150 cell exhibits a smooth membrane (size: $2.2 \times 2.2 \mu \mathrm{m}$ ). (D) 2D and (E) 3D AFM images of KYSE-150 cells treated with $30 \mathrm{mg} / \mathrm{l}$ ART cultured in vitro for $48 \mathrm{~h}$. The cells were irregular in shape and the cell height was increased compared with the control cells (size: $55 \times 55 \mu \mathrm{m}$ ). (F) The ultrastructure of KYSE-150 cells treated with $30 \mathrm{mg} / \mathrm{l}$ ART demonstrated an uneven and rough membrane (size: $2 \times 2 \mu \mathrm{m}$ ) and the nanostructure of the cell membrane appears damaged. (G) 2D and (H) 3D AFM images of SHEE cells cultured in vitro for $48 \mathrm{~h}$. These cells exhibited an oval morphology (size: $40 \times 40 \mu \mathrm{m}$ ). (I) Ultrastructure of SHEE cells displays a smooth membrane (size: $2 \times 2 \mu \mathrm{m}$ ). ART, artesunate; AFM, atomic force microscopy. 
Table I. Cell cycle distribution and levels of apoptosis in KYSE-150 cells prior and subsequent to treatment with ART.

\begin{tabular}{lcccc}
\hline & \multicolumn{3}{c}{ Cell cycle distribution } & \\
\cline { 2 - 3 } Treatment Group & $\mathrm{G}_{0} / \mathrm{G}_{1}(\%)$ & $\mathrm{S}(\%)$ & $\mathrm{G} 2(\%)$ & Apoptosis rate (\%) \\
\hline Control group (0 mg/l, ART) & $54 \pm 1.5$ & $42.5 \pm 2.8$ & $3.5 \pm 0.74$ & $4.53 \pm 0.58$ \\
ART-treatment group (30 mg/l, ART) & $68.1 \pm 0.3^{\mathrm{a}}$ & $11.5 \pm 2.7^{\mathrm{a}}$ & $20.4 \pm 2.53^{\mathrm{a}}$ & $12.45 \pm 0.62^{\mathrm{a}}$ \\
\hline
\end{tabular}

${ }^{\mathrm{a}} \mathrm{P}<0.05$ vs. the control group. ART, artesunate. Data are presented as the mean \pm standard deviation.

A

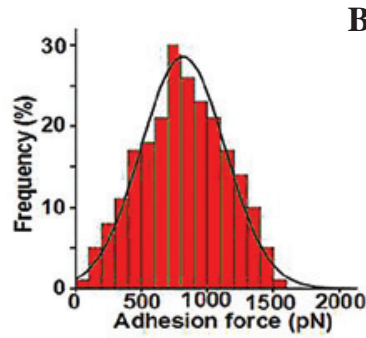

B

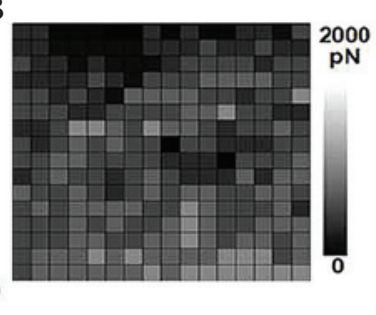

E
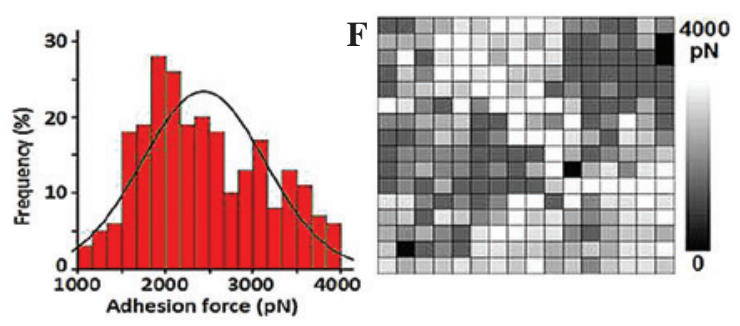

I
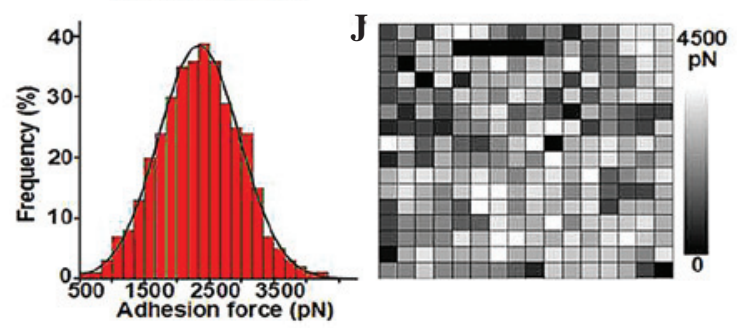

C
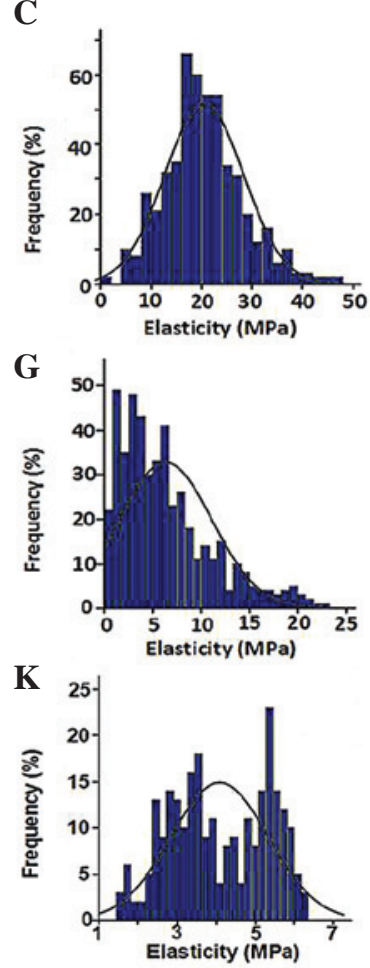

D

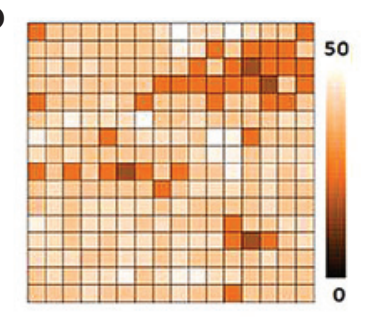

H

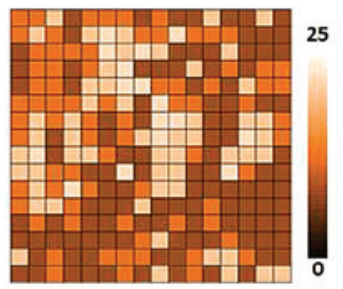

L

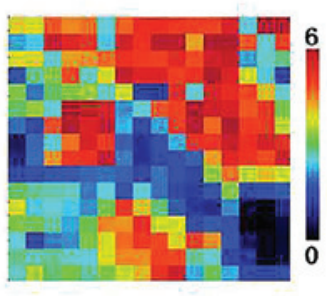

Figure 5. AFM force-distance curve analyses detect adhesive force and elasticity of KYSE-150 and SHEE cells. Control group, KYSE-150 cells without ART treatment: (A) Adhesion force histogram ( $\mathrm{n}=256)$; (B) adhesion force map of the same cell surface area; (C) elasticity histogram ( $\mathrm{n}=256)$; and (D) elasticity map of the same cell surface area. KYSE-150 cells with $30 \mathrm{mg} / 1$ ART-treatment for $48 \mathrm{~h}$ : (E) Adhesion force histogram (n=256); (F) adhesion force map of the same cell surface area; (G) elasticity histogram $(\mathrm{n}=256)$; and $(\mathrm{H})$ elasticity map of the same cell surface area. SHEE group (human normal esophageal epithelial cell line) without ART treatment: (I) Adhesion force histogram ( $\mathrm{n}=256)$; (J) adhesion force map of the same cell surface area; (K) elasticity histogram ( $\mathrm{n}=256$ ); and (L) elasticity map of the same cell surface area. ART, artesunate.

Based on the results of the MTT assay, the most effective concentration of ART $(30 \mathrm{mg} / \mathrm{l})$ was used to measure the cell cycle distribution and apoptosis rates in KYSE-150 cells for $48 \mathrm{~h}$ (Fig. 2). The results demonstrated that the $\mathrm{S}$ phase cell population accounted for $42.5 \pm 2.8 \%$ in the control group, compared with $11.5 \pm 2.7 \%$ in the $30 \mathrm{mg} / \mathrm{l}$ ART group (Table I). The number of cells in $\mathrm{G}_{0} / \mathrm{G}_{1}$ phase increased from $54 \pm 1.5 \%$ in the control group to $68.1 \pm 0.3 \%$ in the ART-treated group, indicating that ART functions as a negative regulator of the cell cycle at the $\mathrm{G}_{1}$-to-S phase transition. The apoptosis rate of the $30 \mathrm{mg} / \mathrm{l}$ ART-treated group was significantly increased at $12.45 \pm 0.62 \%$ compared with the control group at $4.53 \pm 0.58 \%$ (Fig. 2C and D, Table I).

ART mitigates the migration and invasion of ESCC cells. To further detect whether ART is associated with ESCC migration and invasion, a Transwell assay was performed to analyze the effect of ART on the migratory and invasive behavior of KYSE-150 cells. Compared with the control group $(0 \mathrm{mg} / \mathrm{l} \mathrm{ART})$, treatment with $30 \mathrm{mg} / \mathrm{l}$ ART resulted in a significant reduction of cell migration in the KYSE- 150 cell line (Fig. 3A-C). In addition, ART suppressed the normally strong invasive capacity of KYSE-150 cells (Fig. 3D-F). These results indicate that ART reduces cell migration and invasion of ESCC cells in vitro.

The biomechanical properties of KYSE-150 cells treated with ART are similar to that of SHEE cells, detected by AFM. Every cell type possesses a unique structure with specific mechanical properties that can serve as specific biomechanical markers. In the present study, AFM was used to visualize the morphology of SHEE normal esophageal epithelial 
Table II. Biomechanical properties of SHEE and KYSE150 cells prior and subsequent to treatment with ART.

\begin{tabular}{lccc}
\hline Variable & Ra of cytomembrane $(\mu \mathrm{m})$ & Adhesive force $(\mathrm{pN})$ & Elasticity $(\mathrm{MPa})$ \\
\hline $0 \mathrm{mg} / \mathrm{l}$ ART & $0.172 \pm 0.025$ & $800 \pm 300$ & $20 \pm 7$ \\
$30 \mathrm{mg} /$ group & $1.05 \pm 0.088^{\mathrm{a}}$ & $2400 \pm 700^{\mathrm{a}}$ & $7 \pm 4^{\mathrm{a}}$ \\
SHEE & $0.183 \pm 0.026$ & $2300 \pm 600^{\mathrm{a}}$ & $4 \pm 1^{\mathrm{a}}$ \\
\hline
\end{tabular}

${ }^{\mathrm{a}} \mathrm{P}<0.05$ vs. the control group. $\mathrm{pN}=10-12 \mathrm{Newton} ; \mathrm{MPa}=106 \mathrm{~Pa}$. ART, artesunate; Ra, average roughness.

cells and KYSE-150 ESCC cells. Fig. 4 demonstrates that without incubation with ART, the KYSE-150 cells exhibit a spindle-like morphology (Fig. 4B); the KYSE-150 cells treated with $30 \mathrm{mg} / 1$ ART were irregular in shape (Fig. 4E); and the SHEE normal esophageal epithelial cell line was oval in appearance (Fig. 4H). The roughness of membrane ultrastructures of the KYSE-150 cells (Fig. 4C) was similar to that of the SHEE cells (Fig. 4I), but smoother than that of the $30 \mathrm{mg} / \mathrm{l}$ ART-treated group. The cell membrane of the $30 \mathrm{mg} / 1$ ART-treated group was the most irregular and uneven among the three treatment groups (Fig. 4F).

In the KYSE-150 cell line without ART treatment, the adhesive force was $800 \pm 300 \mathrm{pN}$ (Fig. 5A and B); the elasticity force was $20 \pm 7 \mathrm{MPa}$ (Fig. 5Cand D); and the average roughness ( $\mathrm{Ra}$ ) was $0.172 \pm 0.025 \mu \mathrm{m}$ (Table II). Following $30 \mathrm{mg} / \mathrm{l}$ ART treatment in the KYSE-150 cell line, the adhesive force was 2,400 $\pm 700 \mathrm{pN}$ (Fig. 5E and F); the elasticity force was $7 \pm 4 \mathrm{MPa}$ (Fig. $5 \mathrm{G}$ and $\mathrm{H}$ ); and the Ra was $1.05 \pm 0.088 \mu \mathrm{m}$. In the control SHEE cells, the adhesive force was 2,300 $\pm 600 \mathrm{pN}$ (Fig. 5I and J); the elasticity force was $4 \pm 1 \mathrm{MPa}$ (Fig. 5K and L); and the Ra was $0.183 \pm 0.026 \mu \mathrm{m}$. Following incubation with ART $(30 \mathrm{mg} / \mathrm{l})$ for $48 \mathrm{~h}$, the adhesive force and elasticity of KYSE-150 cells was similar to that of the SHEE normal esophageal epithelial cell line (Table II).

\section{Discussion}

In the present study, the effect of the anti-malarial agent ART on ESCC cells was analyzed. Compared with the control group, ART treatment increased the Ra of the cell membrane in addition to the adhesive force. The cell membrane contains numerous different biological macromolecules, including certain sugars, proteins and lipids. These macromolecules transfer signals to cells, form an exchange interface between the inside and the outside of the cell and maintain the integrity and functionality of the cell membrane $(12,23)$. Changes in cell membrane structure can therefore directly influence the cytoskeleton $(13,14)$.

The cytoskeleton is mainly composed of microtubules, microfilaments and intermediate filaments and determines the cell morphology and biomechanical characteristics under different physiological statuses (24). A previous study demonstrated that chromosome stability and cell proliferation are influenced when the cytoskeleton is altered (25). In addition, previous studies have indicated that ART inhibits DNA synthesis and cell growth in several tumor cell lines in vitro $(9,10,26,27)$. The results of the present study for the MTT assay, cell cycle and AFM detection revealed that ART may damage the cytoskeleton to affect signal transduction, DNA synthesis and inhibit cell migration. The results presented in the current study also suggest that ART is a negative regulator of the cell cycle, preventing $\mathrm{G}_{1}$-to-S phase transition. Cell elasticity may reflect alterations in the cytoskeleton and be associated with cell deformation (28), which is inevitable in tumor cell migration and invasion (29). The results of the AFM detection indicated that ART may inhibit the migration and invasion of KYSE-150 cells through suppressing cell elasticity and increasing adhesive force.

Apoptosis serves an important function in maintaining cell homeostasis, and the dysfunction of apoptotic signaling has been implicated in cancer (30). Apoptosis has been studied as a possible target mechanism for anticancer therapy and the cytoskeleton participates in this process; thus, damage of actin in the cytoskeleton may promote apoptosis (31). The results of the apoptosis assay and AFM detection in the present study indicated that ART may increase the apoptosis rate by altering the cytoskeleton of KYSE-150 cells.

In the present study, it was demonstrated that ART is an effective drug for anti-ESCC. ART has the potential ability to inhibit the proliferation, migration and invasion of ESCC cells by affecting their cell morphology and structure.

\section{Acknowledgements}

The present study was supported by the National Natural Science Foundation of China (grant nos. 81272694 and 81071625) to Professor Xiaolong Cheng; the National Natural Science Foundation of China (grant no. 81201956) to Ms. Jing Liu; the Science and Technology Innovation Fund of Shanxi Medical University (grant no. 01201309) to Dr Ruyi Shi; and the Youth Research Fund of Shanxi Medical University (grant no. Q02201202) to Dr Ruyi Shi.

\section{References}

1. Brown LM, Devesa SS and Chow WH: Incidence of adenocarcinoma of the esophagus among white Americans by sex, stage, and age. J Natl Cancer Inst 100: 1184-1187, 2008.

2. White NJ: Qinghaosu (artemisinin): the price of success. Science 320: 330-334, 2008.

3. Youns M, Efferth T, Reichling J, Fellenberg K, Bauer A and Hoheisel JD: Gene expression profiling identifies novel key players involved in the cytotoxic effect of Artesunate on pancreatic cancer cells. Biochem Pharmacol 78: 273-283, 2009.

4. Hou J, Wang D, Zhang R and Wang H: Experimental therapy of hepatoma with artemisinin and its derivatives: in vitro and in vivo activity, chemosensitization, and mechanisms of action. Clin Cancer Res 14: 5519-5530, 2008. 
5. Li LN, Zhang HD, Yuan SJ, Yang DX, Wang L and Sun ZX Differential sensitivity of colorectal cancer cell lines to artesunate is associated with expression of beta-catenin and E-cadherin. Eur J Pharmacol 588: 1-8, 2008.

6. Nam W, Tak J, Ryu JK, Jung M, Yook JI, Kim HJ and Cha IH: Effects of artemisinin and its derivatives on growth inhibition and apoptosis of oral cancer cells. Head Neck 29: 335-340, 2007.

7. Liu WM, Gravett AM and Dalgleish AG: The antimalarial agent artesunate possesses anticancer properties that can be enhanced by combination strategies. Int J Cancer 128: 1471-1480, 2011.

8. Rinner B, Siegl V, Pürstner P, Efferth T, Brem B, Greger H and Pfragner R: Activity of novel plant extracts against medullary thyroid carcinoma cells. Anticancer Res 24: 495-500, 2004

9. Efferth T, Dunstan H, Sauerbrey A, Miyachi H and Chitambar CR The anti-malarial artesunate is also active against cancer. Int J Oncol 18: 767-773, 2001.

10. Efferth T, Sauerbrey A, Olbrich A, et al: Molecular modes of action of artesunate in tumor cell lines. Mol Pharmacol 64: 382-394, 2003

11. Evans EA and Calderwood DA: Forces and bond dynamics in cell adhesion. Science 316: 1148-1153, 2007.

12. Puech PH, Poole K, Knebel D and Muller DJ: A new technical approach to quantify cell-cell adhesion forces by AFM Ultramicroscopy 106: 637-644, 2006.

13. Sato K, Adachi T, Ueda D, Hojo M and Tomita Y: Measurement of local strain on cell membrane at initiation point of calcium signaling response to applied mechanical stimulus in osteoblastic cells. J Biomech 40: 1246-1255, 2007.

14. Voïtchovsky K, Antoranz Contera S, Kamihira M, Watts A and Ryan JF: Differential stiffness and lipid mobility in the leaflets of purple membranes. Biophys J 90: 2075-2085, 2006.

15. Hörber JK and Miles MJ: Scanning probe evolution in biology. Science 302: 1002-1005, 2003.

16. Alonso JL and Goldmann WH: Feeling the forces: atomic force microscopy in cell biology. Life Sci 72: 2553-2560, 2003.

17. Lesniewska E, Milhiet PE, Giocondi MC and Le Grimellec C: Atomic force microscope imaging of cells and membranes. Methods Cell Biol 68: 51-65, 2002.

18. Sugimoto Y, Pou P, Abe M, Jelinek P, Pérez R, Morita1 S and Custance O: Chemical identification of individual surface atoms by atomic force microscopy. Nature 446: 64-67, 2007.
19. Soofi SS, Last JA, Liliensiek SJ, Nealey PF, and Murphy CJ: The elastic modulus of Matrigel as determined by atomic force microscopy. J Struct Biol 167: 216-219, 2009.

20. Kondra S, Laishram J, Ban J, et al: Integration of confocal and atomic force microscopy images. J Neurosci Methods 177: 94-107, 2009.

21. Wang J, Wan Z, Liu W, et al: Atomic force microscope study of tumor cell membranes following treatment with anti-cancer drugs. Biosens Bioelectron 25: 721-727, 2009.

22. Snedecor GW and Cochran WG: Statistical Methods. 7th edition.Iowa State University Press, Ames, IA, USA, pp32-43, 1980.

23. Geiger B, Bershadsky A, Pankov R and Yamada KM: Transmembrane crosstalk between the extracellular matrix - cytoskeleton crosstalk. Nat Rev Mol Cell Biol 2: 793-805, 2001.

24. Fuchs E and Cleveland DW: A structural scaffolding of intermediate filaments in health and disease. Science 279: 514-519, 1998.

25. Saunders WS, Shuster M, Huang X, Gharaibeh B, Enyenihi AH Petersen I and Gollin SM: Chromosomal instability and cytoskeletal defects in oral cancer cells. Proc Natl Acad Sci USA 97: 303-308, 2000.

26. Efferth T, Benakis A, Romero MR, et al: Enhancement of cytotoxicity of artemisinins toward cancer cells by ferrous iron. Free Radic Biol Med 37:998-1009, 2004.

27. Posner GH, McRiner AJ, Paik IH, et al: Anticancer and antimalarial efficacy and safety of artemisinin-derived trioxane dimers in rodents. J Med Chem 47: 1299-1301, 2004.

28. Fletcher DA and Mullins RD: Cell mechanics and the cytoskeleton. Nature 463: 485-492, 2010.

29. Kumar S and Weaver VM: Mechanics, malignancy, and metastasis: the force journey of a tumor cell. Cancer Metastasis Rev 28: 113-127, 2009.

30. Mahoney JA and Rosen A: Apoptosis and autoimmunity. Curr Opin Immunol 17: 583-588, 2005.

31. Gourlay CW and Ayscough KR: A role for actin in aging and apoptosis. Biochem Soc Trans 33: 1260-1264, 2005. 